\title{
Conceptual Design of Experimental Facility for Large-Diameter NTD-Si at the IRT-T Reactor
}

\author{
I. I. Lebedev, D. E. Zolotykh, A. G. Naymushin, N. V. Smolnikov, \\ M. N. Anikin, V. A. Varlachev

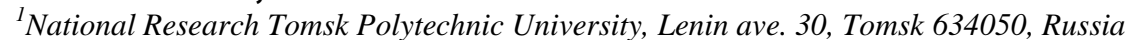

\section{ARTICLE INFO}

Article history:

Received 22 November 2019

Received in revised form 7 December 2020

Accepted 25 December 2020

Keywords:

Neutron transmutation doping of silicon NTD-Si

Thermal neutron filter

Research reactor IRT-T

Neutron flux profile

\begin{abstract}
A B S T R A C T
The IRT-T reactor has been conducting research in the field of irradiation of ingots of single-crystal semiconductor materials since 1987. The article describes the existing silicon doping facility. The results of studies on the possibility of creating an additional irradiation channel for neutron-transmutation doping of silicon are presented. It is shown that the use of a graphite reflector and a thermal neutron filter based on boron makes it possible to achieve non-uniformity of irradiation up to $5 \%$. The principal possibility of irradiating single-crystal silicon ingots with a diameter of up to $203 \mathrm{~mm}$ and a length of up to $500 \mathrm{~mm}$ is shown. The questions of optimizing the configuration of the core and the regime of reactors operation for increasing the neutron flux in the irradiation channels are discussed. In addition, applying the facility to produce base materials for neutron dosimeter in neutron capture therapy studies is proposed.
\end{abstract}

(C) 2021 Atom Indonesia. All rights reserved

\section{INTRODUCTION}

Neutron-transmutation doping (NTD) of silicon is carried out to obtain a semiconductor material with specified properties. Natural silicon contains $3.12 \%$ of the $30 \mathrm{Si}$, which upon neutron absorption is converted to $31 \mathrm{P}$. The reaction can be described as in Eq. (1).

$$
{ }^{30} \mathrm{Si}(n, \gamma){ }^{31} \mathrm{Si} \rightarrow{ }^{31} \mathrm{P}+\beta^{-}
$$

Since in the case of a neutron absorption reaction, the formation of phosphorus nuclei occurs throughout the volume of the doped sample, NTD is the best way to produce large amounts of semiconductor silicon.

Currently, the main manufacturers of semiconductor devices are looking forward to energy silicon with a resistivity of about $60 \Omega \cdot \mathrm{cm}$ or solar-grade silicon with a resistivity of less than 6 $\Omega \cdot \mathrm{cm}$. In the first case, mainly power semiconductor devices are produced for commuting large capacities (in electric vehicles, power devices) while in the

\footnotetext{
*Corresponding author.

E-mail address: nvs38@tpu.ru

DOI: https://doi.org/10.17146/aij.2021.1005
}

latter case silicon is sent for the production of solar batteries.

The main advantages of using NTD technology is the dependence of specific electrical resistance on the time of irradiation by neutrons as in Eq. (2).

$$
t=\frac{A}{\Phi}\left(\frac{1}{\rho_{E}}-\frac{1}{\rho_{A}}\right)
$$

A is the calibration factor $(\Omega / \mathrm{cm})$; $\Phi$ is the thermal neutron flux $\left(\mathrm{cm}^{-2} \mathrm{~s}^{-1}\right) ; \rho_{\mathrm{E}}$ is the target resistivity $(\Omega \cdot \mathrm{cm})$; and $\rho_{\mathrm{A}}$ is the initial resistivity $(\Omega \cdot \mathrm{cm})$.

The demand for increasing the silicon size is growing all the time. In 1980s, for example, the maximum diameter for a doped ingot was $101.6 \mathrm{~mm}$, and nowadays work is underway to develop facilities for the production of semiconductor silicon with a diameter of more than $250 \mathrm{~mm}$.

Figure 1 shows the growth of the diameter of silicon wafers used in microelectronic industry; the circle that is marked orange is the diameter of ingots irradiated at most research reactors.

The enlargement in diameter entails a number of scientific and technical issues, counting from an increasing of the mass-dimensional parameters of 
the facility and ending with the effects of self-absorption in a big size ingot of silicon.

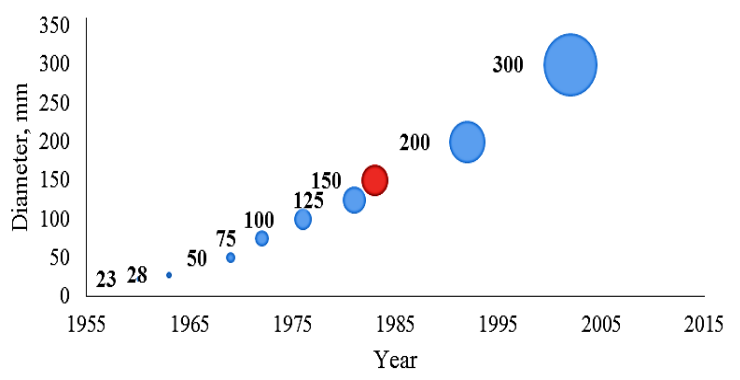

Fig. 1. The growth of the diameter of silicon wafers used in the microelectronic industry; orange marked the diameter of ingots irradiated at most research reactors [1]

Some research reactors have developed facilities for NTD-Si of large diameter. The first one example is the facility at FRM-II reactor (TUM, Germany) which operates at high flux to allow irradiation of silicon ingots up to $500 \mathrm{~mm}$ length and up to $200 \mathrm{~mm}$ diameter. The facility represents itself a vertical channel, mounted in a tank with heavy water asmoderator. To align the axial profile of the neutron field, a nickel-based filter is used. Silicon doping system at the FRM-II reactor allows to dope ingots with unevenness no more than $5 \%$ [1].

Another example is the concept of an installation for doping silicon ingots with a diameter of up to $305 \mathrm{~mm}$ and axial non-uniformity $9 \%$ that is developed in Japan. The base of facility is a graphite prism, the height adjustment of the field is ensured by the movement of the ingot of silicon in the vertical direction [2].

Thus, high demand on doped silicon, good experience in design and the use of NTD-Si of large diameter on research reactors bring us to the idea of development of such facility.

\section{Description of the reactor}

The IRT-T pool reactor was built in 1967. After reconstruction in 1984, its thermal power was increased up to $6 \mathrm{MW}$. The reactor core has a rectangular prism form composed of 20 fuel assemblies of the IRT-3M type [3] (12 eight-tube and 8 six-tube) with $90 \%$ enrichment dispersed UO2-Al fuel in aluminum cladding surrounded by blocks of a beryllium reflector. In the center of reactor core there are 4 beryllium blocks forming central beryllium trap used for production of radioisotopes. The 8 reactor control rods $(\mathrm{KC})$ are placed in the six-tube fuel assemblies and divided into 4 groups. The automatic regulating rod (AR) is located in a beryllium reflector. Large beryllium prism at the right side of reactor core is used as additional reflector for present NTD-Si facility. The geometric dimensions of the core, without internal thermal assembly, are $88 \times 57 \times 50 \mathrm{~cm}$ $(\mathrm{HxLxW})$. Light water is used as moderator, coolant and top biological shield. Lateral biological shield is a tank made of a layer of steel, aluminum and heavy concrete.

The reactor has 16 vertical and 10 horizontal experimental channels, two of them (HEC-1 and HEC-4) are tangential to the core. The uploading area of vertical channels is located at the above-core plane of reactor tank.

The maximum attainable neutron flux density in the center of the core is $1.7 \cdot 10^{14} \mathrm{~cm}^{-2} \mathrm{~s}^{-1}$ [4].

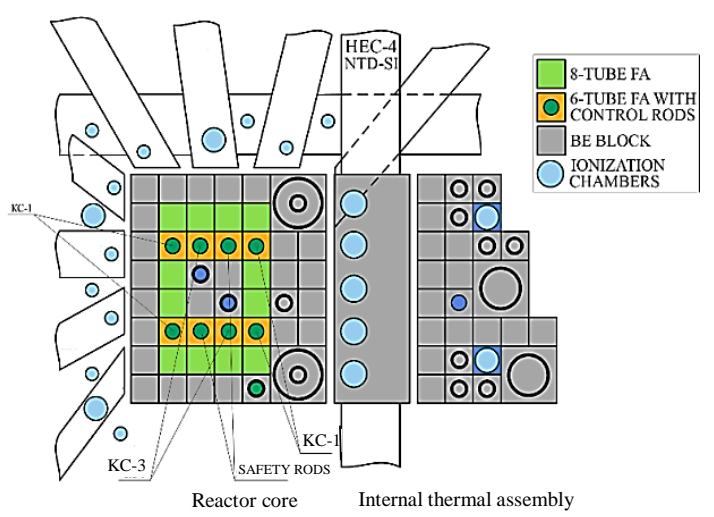

Fig. 2. Schematic representation of the core and experimental channels of the IRT-T reactor.

Top line for shim rods: KC-1-1, KC-3-1, Safety rod-1, KC-2-1; bottom line: KC-1-2, KC-3-2, Safety rod-2, KC-2-2

\section{Currently operating facility for ntd-si at irt-t reactor}

Since 1989 the present facility for NTD-Si has been based on horizontal experimental channel HEC-4 with $150 \mathrm{~mm}$ diameter to allow us to dope ingots up to $125 \mathrm{~mm}$ in diameter and $750 \mathrm{~mm}$ in length using aluminum container diameter of $130 \mathrm{~mm}$. The average thermal neutron flux in the channel is $4 \cdot 10^{12} \mathrm{~cm}^{-2} \mathrm{~s}^{-1}$ [5]. The uploading device of the facility/installation is surrounded by biological shielding made of heavy concrete so that safety conditions throughout ingots irradiation is fully provided (Fig. 3).

In order to form the parameters of irradiation along the length and diameter of the ingots, the movement and rotation of containers along the reactor core is used. All parameters of irradiation, speed of movement and position of ingots in the experimental channel are controlled by the telemetry and control system. The developed irradiation algorithms have made it possible to achieve uniformity of electrical characteristics of the ingots 
more than $93 \%$. The capacity of the current installation is more than 4000 kilograms per year with the nominal electrical resistance of $60 \Omega \cdot \mathrm{cm}$ (approx. time of irradiation is about 30 hours).

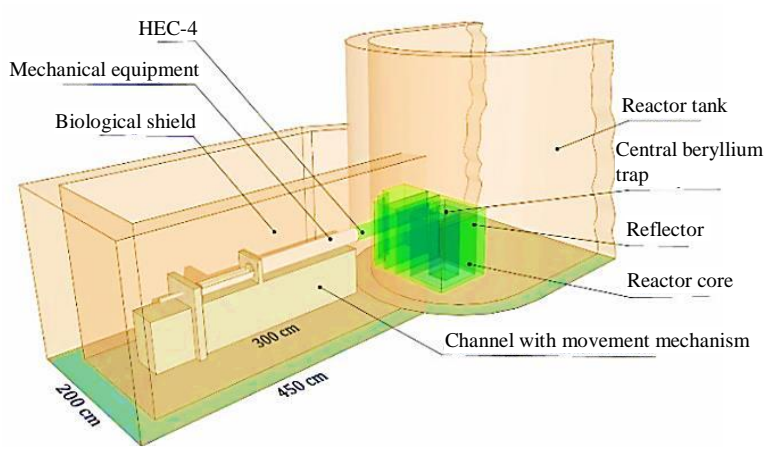

Fig. 3. The scheme of the existing silicon doping unit.

\section{METHODOLOGY}

At the present time the calculating maintenance of the IRT-T reactor is provided by certified precision MCU-PTR code based on Monte Carlo method [6,7].

The detailed geometric model includes fuel assemblies, control rods, beryllium reflector blocks, main structural components, and horizontal and vertical experimental channels. Each fuel assembly is divided into six equal parts in height to account fuel burn-up [8].

For calculations in the current research, as the reference state of the reactor core, the load No. 105 from May 4, 2016 was taken [9]. The average burn-up of fuel across the core was $21 \%$ for $235 \mathrm{U}$. The average position of the shim rods for the groups $\mathrm{KC}-1$ and $\mathrm{KC}-2$ is $28 \mathrm{~cm}$; $\mathrm{AR}-30 \mathrm{~cm}$; $\mathrm{KC}-3$ and safety rods are fully withdrawn.

The influence of poisoning of beryllium reflector by $3 \mathrm{H}, 3 \mathrm{He}$ and $6 \mathrm{Li}$ was taken into account while carrying out computational studies at the beginning of the fuel cycle with respect to the new installed blocks in 2014 [10], which significantly improved the neutron-physical characteristics of the core.

The bottom part of Fig. 4 shows a prism made of reactor graphite with geometrical dimensions of $400 \times 400 \times 800 \mathrm{~mm}$. In the center of graphite prism is placed an experimental channel made of aluminum alloy SAV-1 $1.5 \mathrm{~mm}$ thickness. The internal diameter of the channel is $215 \mathrm{~mm}$. Inside the channel, an ingot of silicon with a diameter of $203 \mathrm{~mm}$ is surrounded by water and installed at the entire height of the prism. Above and below the silicon ingot there are aluminum and reflectors. The silicon ingot is divided into discs
$1 \mathrm{~cm}$ thick to determine the distribution of neutron flux density along the channel height.

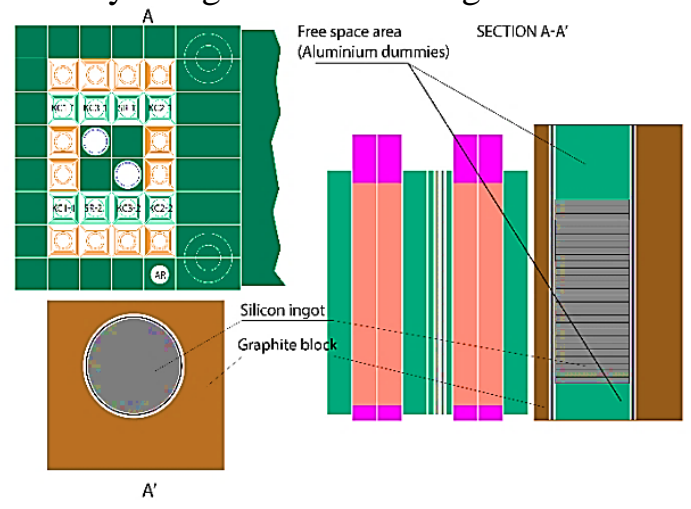

Fig. 4. Horizontal cross-section of model of the IRT-T's reactor core with an additional vertical channel for NTD.

Two neutron flux registration areas were used in calculations: the silicon ingot itself and the boundary area between the beryllium reflector and the graphite prism.

The model was verified by experimental measurement of fluence at the HEC-4 channel. The maximum dispersion between the experimental and calculated values of the integral neutron flux does not exceed $8 \%$, whereas accuracy the thermal neutron flux calculation is $9 \%$.

\section{RESULTS AND DISCUSSION}

As result of substantial upgrading of the reactor IRT-T held in 2014-2015 the installation resource was extended up to 2035. Since the existing channels have a maximum diameter of $150 \mathrm{~mm}$, it was decided to create an additional vertical experimental channel in the free-space of the reactor tank [11]. As far as the preliminary calculations showed the principal possibility of creating such channel, it was necessary to make detailed analysis of the channel design and parameters of irradiation with silicon in it.

Three variants of reflector were considered for forming the spectrum of the neutron flux optimal for silicon doping: metallic beryllium, heavy water and graphite. Graphite is the most preferable to be used as moderator for the ease of handling. According to the concept, a graphite prism should be installed close to the reactor core (Fig. 4) [12].

The position of the experimental channel inside the graphite prism should be determined to obtain the maximum value of thermal neutron flux, and therefore a series of calculations was conducted using MCU-PTR code, throughout of which the experimental channel moved in the longitudinal and transverse directions relative to the core. As a result, the maximum thermal neutron flux $\left(1.49 \cdot 10^{13} \mathrm{~cm}^{-2}\right.$ 
$\mathrm{s}^{-1}$ ) was achieved in order to place the center of the channel at the axis of reactor core at a distance of $5 \mathrm{~cm}$ if it is to count from close to reactor core surface of graphite.

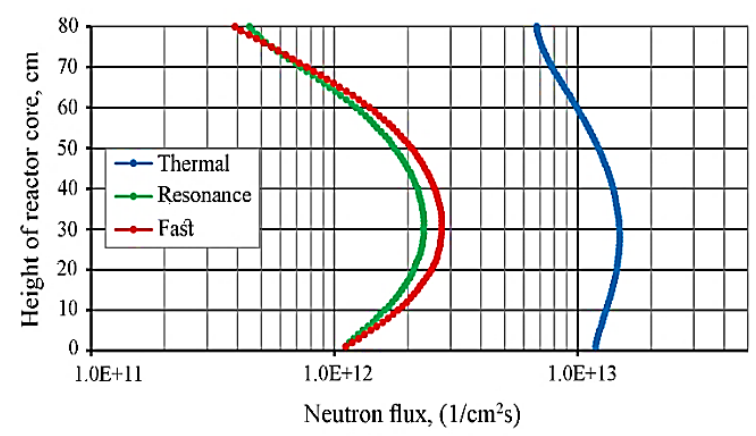

Fig. 5. Dependence of neutron flux distribution on the height of the reactor core.

The axial distribution profile of the neutron flux (Fig. 5) shows the optimal location of the ingot in the channel scales between 10 and $50 \mathrm{~cm}$ from the bottom boundary of reactor core. In contrast to the existing installation, longitudinal motion in the vertical channel cannot be organized so that development of a filter for aligning the neutron field in the axial direction is required. The most suitable design of filter is a thin layer of high absorption compound like boron nitride sprayed onto the external side of the container. Estimation of its influence on the uniformity is carried out by increasing the filter thickness from periphery to the center, and the uniformity is presented in the form of axial distribution of thermal flux (Fig.6).

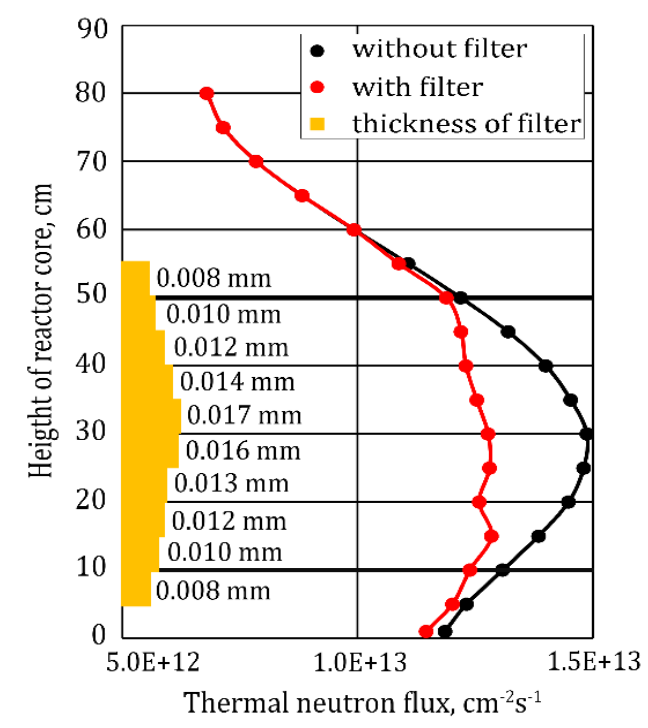

Fig. 6. Neutron flux profile in silicon ingot with and without boron filter.

Variation in the thickness of filter from $0.008 \mathrm{~mm}$ to $0.017 \mathrm{~mm}$ provides non-uniformity of less than $7.5 \%$.
Estimation of radiation non-uniformity is carried out by detailing the ingot model (Fig.7).

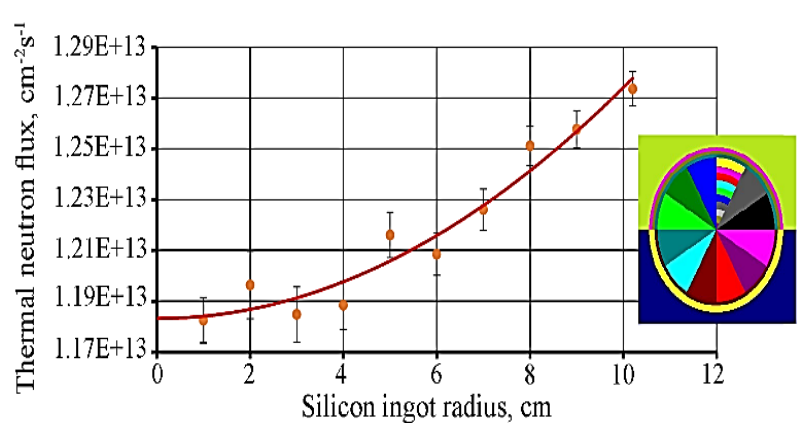

Fig. 7. Radial neutron flux profile in silicon ingot.

The commonly known method based on forced-rotation of the container is chosen for providing and maintaining radial uniformity throughout the irradiation process.

As shown in Fig. 6, there is an influence of water to the vertical thermal neutron flux distribution leading to essential non-uniformity at the periphery compared with the central part of ingot. A way was proposed to increase the neutron flux at the periphery by placing additional reflectors made of graphite or beryllium. The maximum capable thickness of the bottom reflector is $5 \mathrm{~cm}$ while the top reflector has no thickness limitation. Nevertheless, in the case of installing reflector of thickness more than $5 \mathrm{~cm}$, its positive impact starts to reduce because only the first $5 \mathrm{~cm}$ is surrounded by graphite. Another geometric configuration of the additional reflectors was not considered due to technical constraints. The vertical thermal neutron flux profiles in order of reflectors are shown in Fig. 8.

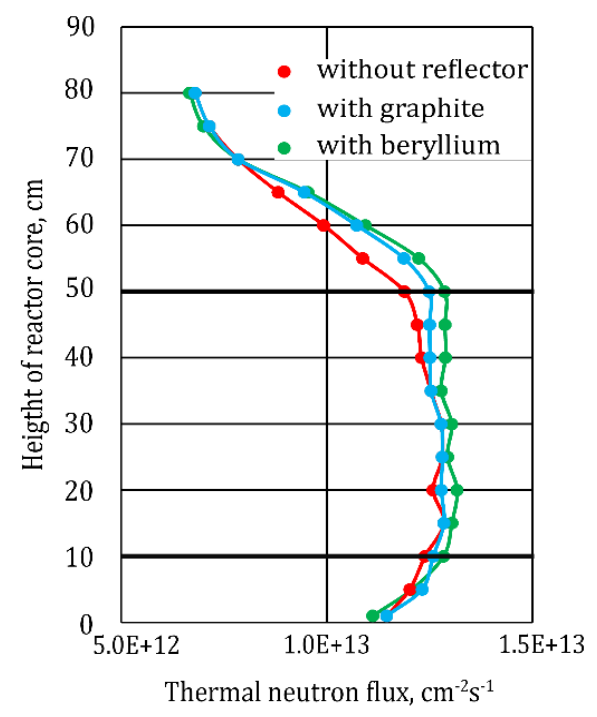

Fig. 8. Flux profile in silicon ingot with two type of top and bottom reflectors. 
The use of beryllium as a plug resulted in a significant increase in both flux of thermal neutrons at the periphery and the average value of thermal flux which increased at $10 \%$ as well as a change in non-uniformity at $1.5 \%$.

Another way to increase the fluence is by optimizing the configuration of the reactor core and operating mode of the control rods movements. In the previous studies it is shown that the safety factor before onset of nuclei boiling of the coolant is more than 2 for the eight-tube and more than 1.8 for the six-tube fuel assemblies. It means that the fuel assemblies can operate in a more loaded mode. Thus, there is a technical possibility to increase the neutron flux in any experimental channel without threats to the reactor safety.

The overcompensation of the control rods is proposed as the way to increase neutron intensity. IRT-T reactor operation carry out by two groups of control rods - KC-1 and KC-2. Groups are moved synchronously, while the rods of the $\mathrm{KC}-3$ group are fully withdrawn during the whole cycle. The groups of rods $\mathrm{KC}-1$ and $\mathrm{KC}-2$ are located symmetrically with respect to the center of the core, so their reactivity worth is roughly the same. When the rod extraction order changes, at which the rods $\mathrm{KC}-1-2$ and $\mathrm{KC}-2-2$ are withdrawn while the $\mathrm{KC}-1-1$ and $\mathrm{KC}-2-1$ rods remain in the core, the neutron flux is redistributed towards the graphite prism. In this case overcompensation leads to an increase of neutron flux density on the surface of the graphite prism at $20 \%$ (Table 1). This may adversely have effects on other experimental devices. Therefore, this opportunity should be used in exceptional cases.

Table 1. Dependence of neutron flux at control rods position

\begin{tabular}{ccc}
\hline \multicolumn{2}{c}{ Control rods position, $\mathbf{m m}$} & $\begin{array}{c}\text { Maximum flux } \\
\text { on graphite surface, } \\
\mathbf{1} \text { KC-1-1, } \mathbf{2} \text { KC-2-1 }\end{array}$ \\
\hline 0 & KC-1-2, KC-2-2 & $5.682 \cdot 10^{13}$ \\
5 & 58 & $5.744 \cdot 10^{13}$ \\
10 & 55 & $5.862 \cdot 10^{13}$ \\
15 & 50 & $5.995 \cdot 10^{13}$ \\
20 & 45 & $6.161 \cdot 10^{13}$ \\
25 & 40 & $6.346 \cdot 10^{13}$ \\
30 & 35 & $6.554 \cdot 10^{13}$ \\
35 & 30 & $6.697 \cdot 10^{13}$ \\
40 & 25 & $6.785 \cdot 10^{13}$ \\
45 & 20 & $6.862 \cdot 10^{13}$ \\
50 & 15 & $6.941 \cdot 10^{13}$ \\
55 & 10 & $6.878 \cdot 10^{13}$ \\
58 & 5 & $6.925 \cdot 10^{13}$ \\
\hline
\end{tabular}

In the present time automatic control rod is located in beryllium block (Fig. 4) nearby the graphite prism. Throughout the campaign of reactor, the range of positions of the rod AR (automatic regulation rod) is between 20 and $40 \mathrm{~cm}$ from the bottom face of the core. That leads to a significant uniformity of the neutron field, which has a negative effect on the quality of irradiation and significantly complicates the design of the filter for aligning the field. Structurally, there is a possibility of replacing the AR rod to another place in the core. The simplest option is to move the AR rod to the opposite side of the core. With such placement, there will not be a negative impact on the safe control of the reactor, and the neutron-physical characteristics (reactivity worth) will not change. The average increase in the neutron flux in the channel is $3.5 \%$. In this case, an optimal neutron flux profile in height is achieved.

Changes in neutron multiplying factor of the reactor core after the graphite prism and the required components were installed is shown in Table 2.

Table 2. Dependence of multiplying properties for different configurations of the irradiation volume

\begin{tabular}{ccccccc}
\hline & $\begin{array}{c}\text { Without } \\
\text { prism }\end{array}$ & Air in the & $\begin{array}{c}\text { Silicon in } \\
\text { channel }\end{array}$ & $\begin{array}{c}\text { Water in } \\
\text { the channel the channel }\end{array}$ & $\begin{array}{c}\text { Prism } \\
\text { without } \\
\text { channel }\end{array}$ \\
\hline$\Delta \rho, \mathrm{pcm}$ & -0.0046 & -0.0013 & 0.0000 & 0.0005 & 0.0021 \\
$\Delta \rho, \beta_{\mathrm{eff}}$ & -0.6398 & -0.1797 & 0.0000 & 0.0756 & 0.2982 \\
\hline \multicolumn{6}{c}{$\Delta \rho=\rho_{\mathrm{i}}-\rho_{\mathrm{Si}}$} \\
\hline \multicolumn{6}{c}{}
\end{tabular}

\section{CONCLUSION}

As a result of the study, the principal design of an additional channel for irradiating silicon with a diameter of up to $203 \mathrm{~mm}$ in research reactor IRT-T has been developed. The principal possibility of increasing the average neutron flux at $3.5 \%$ at the experimental channel may be achieved by changing the regulation of rod motion and optimizing the configuration of the core. In the case of overcompensation of control rods, increase in neutron flux density was observed.

The proposed filter, consisting of an aluminum tube with sputtered boron carbide, makes it possible to achieve an axial non-uniformity value of $5 \%$. A method to increase the length of the irradiated ingots by the use of additional end reflectors made of beryllium is proposed.

It should be noted that there is a steady state calculation, i.e., not taking into account the movement of the control rods and the uneven fuel burn-up during the campaign.

Beside the use of irradiated silicon for electrical devices production, application of silicon as neutron detector for medical purposes is proposed, particularly in neutron capture therapy 
studies because the detector diameter is comparable with the size of radiation beam of clinical facilities. Therefore, silicon based detector may provide opportunity for detail dosimetry of neutron dose during irradiation process in clinical studies.

\section{ACKNOWLEDGMENT}

This work was performed on the large-scale facility IRT-T research reactor.

The research was funded from Tomsk Polytechnic University CE Program grant.

\section{AUTHOR CONTRIBUTION}

I.I Lebedev and D.E. Zolotykh are the main contrubutors to this paper. A.G. Naymushin is the author who provided the methodology and supervision. V.A. Varlachev has provided the methodology of research. N.V. Smolnikov and M.N. Anikin contributed as authors working on methodology, software, and investigation.

\section{REFERENCES}

1. X. Li, H. Gerstenberg, and I. Neuhaus, Appl. Radiat. Isot. 67 (2009) 1220

2. M. Yagi, M. Watanabe, K. Ohyama et al., Appl. Radiat. Isot. 67 (2009) 1225.
3. A. Naymushin, Y. Chertkov, I. Lebedev et al., IOP Conf. Ser.: Mater. Sci. Eng. 93 (2015) 012002.

4. M.V. Shchurovskaya, V.P. Alferov, N.I. Geraskin et al., IOP Conf. Ser.: J. Phys. Conf. Series 781 (2017) 012025.

5. V.A. Varlachev, A.V. Golovatsky, E.G. Emets et al., IOP Conf. Ser.: Mater. Sci. Eng. 135 (2016) 012047.

6. M.V. Shchurovskaya, V.P. Alferov, N.I. Geraskin et al., Ann. Nucl. Energy 96 (2016) 332.

7. M.A. Kalugin, D.S. Oleynik and D.A. Shkarovsky, Ann. Nucl. Energy 82 (2015) 54.

8. A. Naymushin, M. Anikin, I. Lebedev et al., J. Ind. Pollut. Control 32 (2016) 449.

9. A. Naymushin, Y. Chertkov, M. Shchurovskaya et al., IOP Conf. Ser.: Mater. Sci. Eng. 135 (2016).

10. M.V. Shchurovskaya, V.P. Alferov, N.I. Geraskin et al., Ann. Nucl. Energy 113, (2018) 436.

11. A. Naymushin, Y. Chertkov, I. Lebedev et al., J. Ind. Pollut. Control 32 (2016) 424.

12. A. Mochalov, A. Naymushin, V. Nesterov et al., J. Ind. Pollut. Control 32 (2016) 432. 